\title{
Multiforme erythema complicating an orf
}

\author{
Afaf Khouna ${ }^{1}$, Sabah Bazouti ${ }^{1}$, Nassiba Zerrouki ${ }^{1}$, Loubab Omahsan', Nada Zizi ${ }^{1,2}$, \\ Siham Dikhaye ${ }^{1,2}$
}

\author{
${ }^{1}$ Department of Dermatology, Mohammed VI University Hospital of Oujda, Medical School of Oujda, Mohammed First \\ University of Oujda, Oujda, Morocco, ${ }^{2}$ Department of Epidemiology, Clinical Research and Public Health Laboratory, \\ Medical School of Oujda, Mohammed First University of Oujda, Oujda, Morocco
}

Corresponding author: Dr. Afaf Khouna, E-mail: afaf.khouna@gmail.com

\begin{abstract}
Orf, also known as ecthyma contagiosum, is a spontaneously zoonotic epitheliotropic skin infection caused by a parapox virus. The disease develops in sheep and goats. The virus can also infect humans who come into contact with active lesions, or with their products. Erythema multiforme is considered to be a rare complication of Orf's disease. We report the case of a young Moroccan woman, who presented an Orf complicated of multiforme erythema, appeared 8 days after the Feast of Sacrifice, having well heal under symptomatic treatment. Orf is capable of causing epidemics after the Sacrifice Feast in Muslim countries, therefore information on the disease as well as the precautions to be taken, should be provided to groups at risk.
\end{abstract}

Key words: Orf, Multiforme erythema, Virus sacrifice, Feast animals

\section{INTRODUCTION}

Orf, also known as contagiosum ecthyma, is a spontaneously zoonotic epitheliotropic skin infection caused by a parapox virus of the group of DNA viruses. The name of the disease is an Irish word for sheep disease. It develops in sheep and goats generally in spring and summer [1]. Orf virus is usually transmitted through the breaks and abrasions on the skin. Farmers, butchers, sheep shearers and veterinarians are prone to diseas [2]. Multiforme Erythema is often associated with Herpes simplex virus infection or Mycoplasma pneumoniae [3]. It rarely complicates Orf's disease [4]. We report the case of a young Moroccan woman with multiforme erythema generated by an Orf, appeared few days after the Sacrifice Feast which has well heal under symptomatic treatment.

\section{CASE REPORT}

She was a 31-year-old woman, of Moroccan origin, without significant pathological history, who was presented to the emergency department, for acral cutaneous lesions, appeared 8 days after a skin break with a knife used during the Feast of Sacrifice. The patient did not report any recent herpes infection or recent pulmonary symptomatology.

She was stable, apyretic $\left(37.2^{\circ}\right)$. Clinical check has found multiple pseudocockades and some cockades lesions, with 3 concentric areas: an peripheral erythematous disc, a paly middle disc and a central zone sometimes vesicular and sometimes crustal, affecting both hands and feet (Fig. 1). We had also noted the presence of a rounded nodule, purplish- red, well-defined, $1.5 \mathrm{~cm}$ long axis, with hard consistency, painful on palpation, on the $2^{\text {nd }}$ phalanx of the $3^{\text {rd }}$ finger of the left hand (Fig. 2).

The biological assessment revealed an inflammatory syndrome with a slight hyperleucocytosis dominant by PNN, and a CRP at $32 \mathrm{~g} /$. Local care and symptomatic analgesic treatment were prescribed for the patient. The evolution of the cas has been marked by the patient recovering with a total disappearance of the lesions after about twenty days.

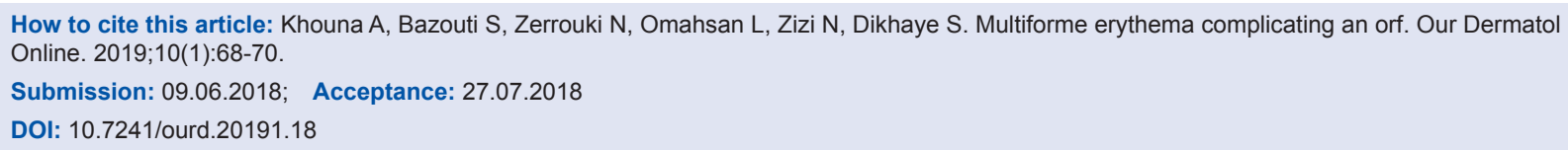




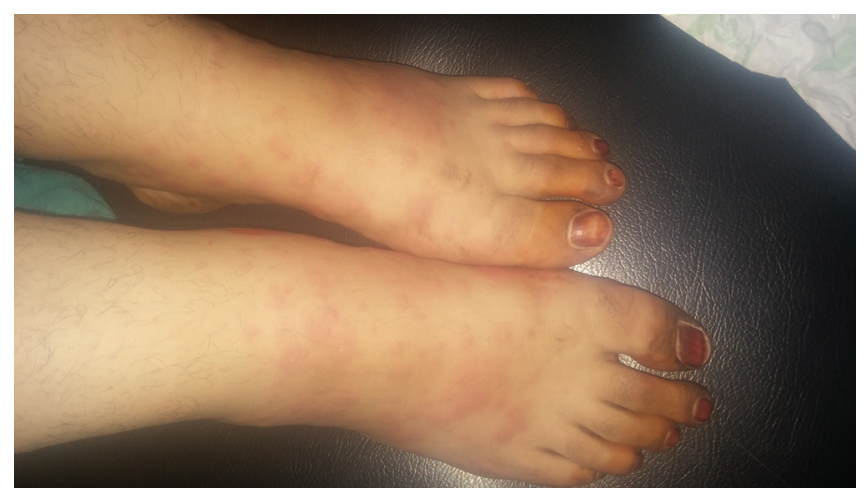

Figure 1: Clinical image showing feet'spseudocockades.

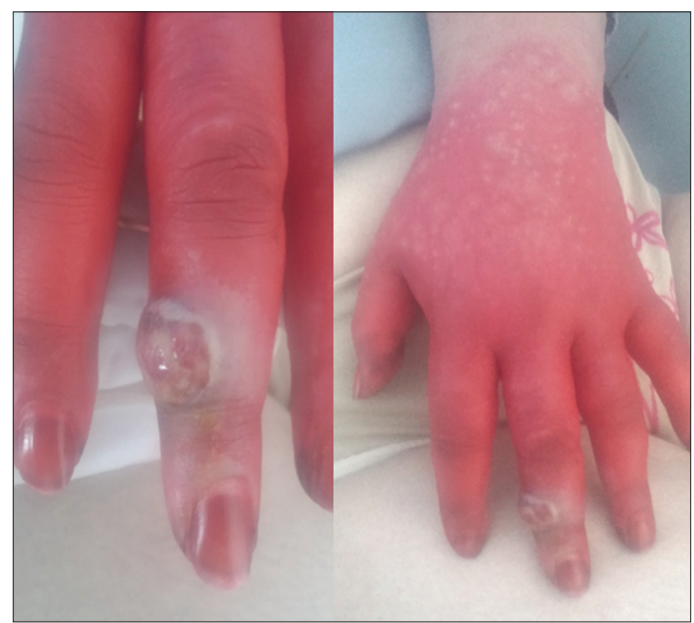

Figure 2: Clinical image of Orf nodule in the left hand.

\section{DISCUSSION}

Orf is not an endemic disease, but it may cause epidemics after the Sacrifice Feast in Muslim countries [1]. It is more common among butchers (24.4\%) before the Sacrifice Feast, and among those who slaughter animals (40.5\%) after. With a male predominance $(30.4 \%)$ before the Feast, and femininepredominance $(32.7 \%)$ after that. The results were consistent in several countries, notably Turkey and Tunisia [5].

The incubation period goes from 3 to 10 days, with single or multiple lesions affecting mainly hands and the face [6]. For humans, the Orf goes through six clinical stages, each lasting nearly a week. The disease begins with the appearance of an erythematous papule that turn to be a nodule " of target " type, red in the center and white in the borders, surrounded by a red ring, then the lesion regresses leaving place for a thick crust that develops on the lesion before it disappears without a trace [1]. The diagnosis is clinical, but in some cases the virus isolation, tissue culture or polymerase chain reaction
(PCR) may be useful, however they still be expensive and not common [6]. In our patient, the appearance of lesions during the Feast of Sacrifice, after contact with a sheep, as well as the typical clinical and evolutionary aspect of the lesion, was sufficient to retain the diagnosis.

Lesions might be complicated by lymphangitis or secondary bacterial infection, but systemic complications such as multiforme erythema and generalized lymphadenopathy are rare [6]. Multiforme Erythema is an acute eruptive syndrome characterized by the acral lesion in the roundel. It is most often associated with Herpes simplex virus infection or Mycoplasma pneumoniae infection [3]. The association of an Orf and an multiforme erythema has rarely been described in the literature. This complication is related to an immune response caused by contagiosum ecthyma [4]. In our case it was a minor multiforme erythema complicating an Orf, having evolved well under symptomatic treatment.

In general, conservative therapy and local antiseptic are recommended to prevent bacterial infection, but cryotherapy or topical cidofovir cream can be used for large lesions. Low-dose of systemic steroids and antihistamines are useful in the treatment of multiforme erythema [6].

\section{CONCLUSION}

Orf is a zoonotic viral infection, able of causing epidemics after the Sacrifice Feast in Muslim countries [1].

Therefore, care should be taken when coming into contact with sheep or goats with ecthyma, through the use of gloves and the disinfection of contaminated areas. We believe that more information about the disease, including vaccination and treatment of affected animals should be provided to groups at-risk, such as breeders, as well as to the general population, especially during Sacrifice days [1].

\section{CONSENT}

The examination of the patient wasconductedaccording to the Declaration of Helsinki principles.

\section{REFERENCES}

1. Saçar H, Uyar B. Investigation of the complications and incidences of orf disease during and after the Feast of the Sacrifice period. Dermatol Sinica. 2015;33:191-5. 
www.odermatol.com

2. Tamer F, Yuksel ME. The spectacular presentation of orf disease. Our Dermatol Online. 2018;9:152-3.

3. Saada D, Velasco S, Vabres P, Guillet G. Érythème polymorphe majeur et infection à Chlamydia pneumoniaE. Ann Dermatol Vénéréol. 2006;133:1001-4.

4. Larquey M, Mahé E. Echtyma contagiosum compliquè d'érythéme polymorphe: à propos d'un case. Arch Pédiatr. 2016;23:1184-90.

5. Khaled A, Robbana F, Hammami H, Kharfi M, El Fekih N, Fazaa B, et al. Orf of the han. Tunis Med. 2009;87:352-3.
6. Biazar T, Shokri M. Erythema Multiforme as a Result of Orf Disease; a Case Report. Emerg (Tehran). 2016;3:163-5.

Copyright by Afaf Khouna, et al. This is an open access article distributed under the terms of the Creative Commons Attribution License, which permits unrestricted use, distribution, and reproduction in any medium, provided the original author and source are credited.

Source of Support: Nil, Conflict of Interest: None declared. 